\title{
ASSESSMENT OF SMOKING BEHAVIOR AMONG MALAY MALE SMOKERS IN KELANTAN, MALAYSIA
}

\author{
SITI KHARIEM SOPHIA M ${ }^{1 *}$, NURIWANI AR ${ }^{1}$, IMRAN AHMAD ${ }^{2}$, RUZILAWATI AB ${ }^{1}$
}

${ }^{1}$ Department of Pharmacology, School of Medical Sciences, Universiti Sains Malaysia, Kelantan, Malaysia. ${ }^{2}$ Department of Family Medicine School of Medical Sciences, Universiti Sains Malaysia, Kelantan, Malaysia. E-mail: tieimran@yahoo.com

Received: 23 September 2016, Revised and Accepted: 27 October 2016

\section{ABSTRACT}

Objective: The aim of this study was to assess smoking behavior among Malay male smokers in Kelantan, Malaysia.

Methods: Volunteers ( $\mathrm{n}=496)$ were recruited in the study by randomly selected manner. The participants were categorized as smokers (n=248) and non-smoking controls $(n=248)$. All participants were given data collection sheets to record their information. The participants who were selected in smokers group $(n=248)$ were given a form containing questionnaires regarding their smoking behavior. The participants were asked about their smoking history such as smoking initiation age, factors that influence smoking behavior, number of cigarettes daily, number of quitting attempts, and methods of quitting attempts. The validated Malay version of Fagerstrom test for nicotine dependence (FTND-M) was used to measure physical dependence on nicotine among smokers.

Results: The study revealed that smokers in this study group were mainly light smokers. More than half of the participants, i.e., $51.6 \%$ (n=128), in this study had an FTND-M score lower than 2 (very low nicotine dependence). The minimum smoking initiation age of the participants in this study was 10 years whereas the maximum age was 40 years. Most of the participants start smoking at the age of $<20$ years with the higher frequency being 18 years. More than half of the participants (58.5\%) claimed that peer influence is the main factor initiating their smoking behavior. From the study, about 50.4\% ( $\mathrm{n}=125)$ of participants used <10 sticks of cigarettes per day, 39.1\% (n=97) used 11-20 sticks, 9.39\% (n=23) used 21-30 sticks, while $1.2 \%$ of the participants used more than 31 sticks of cigarettes per day. Our data indicate that only $10.9 \%$ ( $\mathrm{n}=27$ ) of participants had tried more than 5 times to quit smoking. Even though new effective treatments are now available, almost half of the participants, i.e., $51.6 \%$ (n=128), had tried to quit smoking without any intervention.

Conclusion: Data obtained from this study later may help the public health policy makers and practitioners, especially in Kelantan, Malaysia, to make smoking prevention strategies more effective.

Keywords: Smoking behavior, Male smoker, Malay male and smoking assessment.

(c) 2017 The Authors. Published by Innovare Academic Sciences Pvt Ltd. This is an open access article under the CC BY license (http://creativecommons. org/licenses/by/4. 0/) DOI: http://dx.doi.org/10.22159/ajpcr.2017.v10i2.15335

\section{INTRODUCTION}

Tobacco consumption is well known as a leading cause of preventable morbidity and mortality worldwide. Over a decade, cigarettes smoking cause many public health problems and becoming more important to focus. It is a major contributor to many diseases such as stroke [1], heart disease [2,3], chronic obstructive pulmonary disease [4], periodontal disease [5], peripheral vascular disease [6], pneumonia [7], lung cancer [8], and oral cancer [9].

In Malaysia, smoking-related diseases have been the primary cause of mortality for the past three decades. It is estimated that one-fifth of disability adjusted life years and one-third of years of life lost for Malaysians were due to smoking-related diseases [10,11]. According to the Ministry of Health Malaysia (MOH), tobacco use in Malaysia accounts for $35 \%$ of in-hospital deaths, principally from cancer, heart disease, and stroke. More than 10,000 Malaysians die from smoking-related illnesses each year [12]. Statistics from the MOH in 2006 revealed that diseases related to smoking remained the top causes of death in MOH hospitals, accounting for more than 15\% of hospitalizations and $35 \%$ of in-hospital deaths. Heart diseases and diseases of pulmonary circulation ranked first, accounting for $15.7 \%$ of these deaths, followed by malignant neoplasms (10.6\%) and cerebrovascular diseases $(8.5 \%)$ [12].

The objective of this study was to assess smoking behavior among Malay male smokers in Kelantan, Malaysia. Data obtained from this study later may help the public health policy makers and practitioners, especially in Kelantan, Malaysia, to make smoking prevention strategies more effective.

\section{METHODS}

\section{Subjects}

Overall, 496 volunteers were recruited. The participants were categorized as smokers $(n=248)$ and non-smoking controls $(n=248)$. To be included in the study, smokers were defined as having smoked more than 100 cigarettes in a lifetime and being a current smoker at the time of the study [13]. Non-smokers were defined as volunteers who never smoked cigarettes. Ex-smokers or those who had stopped smoking before the study were excluded from the study. Other exclusion criteria included history of cancer, coronary heart disease, liver disease, and undergoing treatment for drug addiction. The participants were informed about the experimental procedures and aim of the study before giving written informed consent. All participants were given data collection sheets to record their information. The data collection sheets were given based on smoking status group. Smoking history and family background of the participants were obtained. All participants who aged 18-50 years were included in the study. The study protocol was approved by our Local Research and Ethics Committee, School of Medical Sciences, Universiti Sains Malaysia.

\section{Smoking behavior assessment}

Smoking behavior was assessed with a questionnaire concerning tobacco use. Participants who were selected in smokers group $(n=248)$ were given a form containing questionnaires regarding their smoking 
behavior. Participants were asked about their smoking history such as smoking initiation age, factors that influence smoking behavior, number of cigarettes daily, number of quitting attempts, and methods of quitting attempts.

\section{Fagerstrom test}

The Fagerstrom test for nicotine dependence (FTND) is a widely used six-item questionnaire, which was used as a measure of physical dependence on nicotine [14]. The higher the Fagerstrom score, the more intense is the individual's physical dependence on nicotine. In this study, we used the validated Malay version of FTND-M [15]. The form was given to each participant who has been identified as smoker. The three yes/no items are scored 0 (no) and 1 (yes). The three multiplechoice items are scored from 0 to 3 . The items are summed to yield a total score of $0-10$. The score of the participants was calculated, and they were classified into five-level categorizations: Very low nicotine dependence (0-2), low nicotine dependence (3-4), moderate nicotine dependence (5), high nicotine dependence (6-7), and very high nicotine dependence (8-10) according to the score.

\section{Statistical analysis}

Demographic data of participants were analyzed using Independent sample t-test and Mann-Whitney test. $\mathrm{p}<0.05$ was considered statistically significant. All statistical analyses were performed using the SPSS package version 20 (IBM, Armonk, NY).

\section{RESULTS AND DISCUSSION}

A total of 496 Malay male individuals were selected based on the study's exclusion and inclusion criteria. The participants were divided into two groups comprising 248 smokers and 248 nonsmokers.

In our study, we focus on Malay male population aged between 18 and 50 years. According to the Global Adult Tobacco Survey Malaysia (GATS Malaysia) in 2011, Malay ethnic has the highest number of daily smokers compared to other ethnics. Among the three main ethnic groups in Malaysia, $22.3 \%$ of Malays, $17.2 \%$ of Indians, and $14.2 \%$ of Chinese were daily smokers. The proportions of non-smokers were $84.6 \%$ of Chinese, $80.4 \%$ of Indians, and $75.4 \%$ of Malays. Thus, this study was focusing only on the pure Malay individuals. To fulfill these criteria, we have selected Malay male individuals from three generations of Malay ethnic group (his father and mother, grandfather, and grandmother must be Malay). This is to avoid ethnic bias since Malaysia has multiethnic population, which can contribute to the trait of the individual.

Only male individuals were recruited in this study. One of the reason was smokers are more prominent in male. The GATS Malaysia reported $23.1 \%$ or 4.75 million Malaysian adults aged 15 years or older were current smokers of tobacco with $43.9 \%$ (4.64 million) of men and $1.0 \%$ (0.10 million) of women. According to Kahende et al. [16], in general, smoking may be up to five times more prevalent among men than women in some communities although the gender gap usually declines with younger age. In Egypt, for example, the prevalence of smokers among men was $97 \%$ compared to women and was higher among adults under the age of 45 years [17]. In the United States, smokers were more prevalent among men (20.5\%) than women (15.3\%) [18]. The first study on smoking habits in Sweden was performed in 1946 when $50 \%$ of men and $9 \%$ of women were smokers; in $1977,32 \%$ of women and $41 \%$ of men were smokers. In Algeria, the smoking rate for men was $29.9 \pm 2.5$ whereas for women was $0.3 \pm 0.2$ [17].

Demographic data for the two groups such as age, weight, height, blood pressure (BP), and body mass index (BMI) were recorded and are shown in Table 1. There were no significant differences between the two groups for all the parameters except for age and brachial systolic blood pressure. Results were expressed as mean (standard deviation) for weight, height, BMI, and brachial systolic and diastolic blood pressure. The result was expressed as median (interquartile range) for age. The median age for nonsmokers group was $24.0(16.0)$ years and for smokers group was 33.5 (19.0) years.

Based on the demographic data of the participants in this study, age and systolic BP showed significant difference between smokers group and nonsmokers group. The age of the participants in our study was selected between 18 and 50 years. The average age for non-smoker group was in the 20 s while in smokers group was in the 30 s. One reason could be that most of the males of nonsmoker group were recruited from institute of higher education which is Maktab Perguruan Pengkalan Chepa, Kelantan, Malaysia (College for teacher education) and Universiti Sains Malaysia. While compared to smoker group, participants were recruited in various locations in Kota Bharu, Kelantan, Malaysia. This supports the interpretation that the community and school level variables are predictive of adolescent smoking [19]. School achievement has been shown to be a strong predictor of smoking behavior [20].

Numerous cross-sectional studies indicate that body weight or BMI is lower in cigarette smokers than in nonsmokers [21,22]. Smoking's effect on body weight could lead to weight loss by increasing the metabolic rate, decreasing metabolic efficiency, or decreasing caloric absorption (reduction in appetite), all of which are associated with tobacco use. The metabolic effect of smoking could explain the lower body weight found in smokers [23]. Nicotine reduces body weight by raising the resting metabolic rate while blunting the expected increase in food intake in response to the increase in metabolic rate [24]. However, there is no significant difference observed between smokers and nonsmokers in terms of age and BMI in this study. The result is consistent with Schindler-Ruwisch et al. [25] that reported smokers have BMIs similar to the general population, for instance nonsmoker population. One possible reason could be the difference between the averages age of the nonsmoker group and smoker group. Studies show that increasing age will change body's composition and fat storage. This is due to the metabolism changes, less muscle mass, and increase body fat mass that impact the speed and degree of fat accumulation [26,27].

The significantly lower systolic BP between smokers compared to nonsmokers in this study might be because of various reasons. The study done by Mikkelsen et al. [28] demonstrated that the smokers presented lower mean daytime systolic BP readings. They suggested that this outcome was caused by an adaptive effect in the sympathetic nervous system after numerous years of exposure to nicotine. The authors emphasized that smoking also helps reduce stress, which could be associated with the lowering of BP [28]. A vasodilator effect of cotinine which is the major metabolite of nicotine also may contribute

Table 1: Demographic data of participants involved in the study

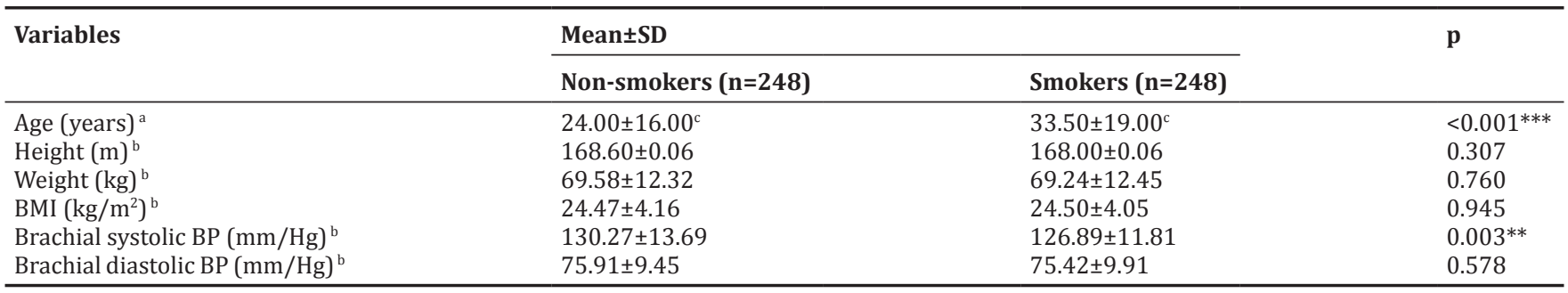

${ }^{\mathrm{a}}$ Mann-Whitney test, ${ }^{\mathrm{b}}$ Independent samples t-test, ${ }^{\mathrm{c}}$ Median. ${ }^{* *} \mathrm{p}<0.01,{ }^{* * *} \mathrm{p}<0.001$. SD: Standard deviation, BMI: Body mass index, BP: Blood pressure 
to the lower blood pressure. Cotinine relaxes vascular smooth muscle and dilates blood vessels in vitro [29].

Smoking initiation was defined as the age at which an individual first smoked a whole cigarette [30]. The minimum smoking initiation age of the participants in this study was 10 years whereas the maximum age was 40 years. Most of the participants start smoking at the age of $<20$ years with the higher frequency being 18 years. The GATS Malaysia reported that more than half (51.8\%) of those aged $20-34$ years and who had ever smoked on a daily basis had started smoking daily before the age of 18 years. This is consistent with the studies done by Bawazeer et al. [31], Felimban and Jarallah [32], and Haddad and Malak [33], which found that the most common age of smoking initiation was between 15 and 19 years among all smokers. According to Young et al. [34], the great majority of smokers start the habit before 20 years of age. In the United Kingdom, over $80 \%$ of adult populations started smoking before the age of 20 years [35].

There are many reasons for smoking, such as alleviation of stress, life problems, peer pressure, social acceptance issues, family history (parental modeling of smoking behavior), lower educational attainment, and lower economic status [33]. Young smokers desire to appear mature, self-confident, and independent and to attain a high personality profile [36]. Smith and Stutts [37] reported that the most important factors associated with smoking are family smoking behavior and peer pressure [37]. These statements support our result on the factors that influence smoking behavior. More than half of the participants (58.5\%) in this study claimed that peer influence is the main factor initiating their smoking behavior (Table 2) while 23.8\% (n=59) participants chose stress and $16.5 \%(n=41)$ participants being a smoker by their own desire in initiating their smoking behavior. However, only $1.2 \%$ of participants choose influence by family member. The strength of the influence from family and friends may depend on the quality of their social bond with the individual. As mentioned before, the average age of smoking initiation for smoker in this study is $<20$ years of age. Thus, taking into account that adolescence is a period of increasing bonds with peers and possibly of weakening bonds with parents, smoking among friends might have more influence on adolescent smoking behaviors. According to Khuder et al. [38], adolescents are more likely to smoke if they associate with others who are smokers. Being away from family, experiencing stress from studies and new adulthood are also factors associated with student smoking taking into account that most of our participants are university and college students.

All participants were asked whether there has been any family member in their family that has been a smoker. The question "Is there anyone in your family who smoke?" was given to both group nonsmoker and smoker. A significant association was observed between the smoking status and the family members who smoke (Table 3 ). There was highly significant difference observed between smoking status and participants who have family members who smoke $(\mathrm{p}<0.001)$. For smoker groups, the frequency of individual who has smoker in their family member was $93.5 \%(n=232)$ while individual who does not have smoker among their family member was $6.5 \%(n=16)$. Compared to nonsmoker group, the frequency of individual with smoker family member was $63.3 \%$ $(\mathrm{n}=157)$, and $36.7 \%(\mathrm{n}=91)$ for individual who has no smoker among family members. This result showed that genetic and environment factors may influence people to become a smoker. The development of nicotine dependence in individuals requires nicotine exposures. The initiation to smoke has been associated with family risk factors, such as parental smoking, family protective factors including a strong parentchild relationship, and also the influence by family members. According to So and Yeo [39], having a family that approves of smoking in the home was significantly associated with early smoking initiation. Several studies have shown that parental smoking has an impact resulting in a higher risk of smoking initiation, escalation, and the persistence of adolescent smoking [40-42]. Previous studies that focus on the effects of smoking siblings on adolescent also reported that smoking sibling increases the likelihood of smoking among adolescents [38,43]. The association observed between smoking status and the existence of smoker in family member in this study might also suggest that genetic factor might be the reason of this positive result. People who have family member who smoked may have higher tendency to be a smoker as they have the same genetic made up. Parental and sibling smoking is a strong and significant determinant of the risk of smoking uptake by young people [44].

From the result (Table 2), about 50.4\% (n=125) of participants used $<10$ sticks of cigarettes per day, 39.1\% ( $\mathrm{n}=97$ ) used 11-20 sticks, $9.39 \%$ $(n=23)$ used 21-30 sticks, while $1.2 \%$ of the participants used more than 31 sticks of cigarettes per day. In 2011, the GATS Malaysia reported that on average, a daily Malaysian adult smoker smoked 14 cigarettes per day.

All smokers were asked if they had ever tried to quit. Smokers were asked how many attempts they had made to quit smoking. Our data indicate that only $10.9 \%(n=27)$ had tried more than 5 times (Table 2). About $49.6 \%(n=123)$ of the smokers in this study had tried to quit smoking 2-5 times in their life. It is clear that most smokers made repeated attempts to quit smoking. While $26.2 \%(n=65)$ had tried once in their lifetime, it is interesting to note that $13.3 \%(n=33)$ were never made a serious quit attempt. According to Ary and Biglan [45], smokers who attempt to quit smoking need effective skills to overcome high exposure to smoke.

Another important indicator of whether smokers are seriously thinking about quitting is the methods that the participants used to quit smoking. Even though new effective treatments are now available, almost half of the participants, i.e., $51.6 \%(n=128)$, had tried to quit smoking without any intervention. About $28.6 \%(\mathrm{n}=71)$ participants used candy and $4.8 \%(n=12)$ tried with nicotine replacement method while $0.8 \%(n=2)$ used traditional method and other method such as exercise (Table 2).

\section{Table 2: Summary of the participants' smoking history}

\begin{tabular}{ll}
\hline Characteristics & $\mathbf{n}(\mathbf{\%})$ \\
\hline Factor influencing smoking behavior among smokers & \\
Peer influence & $145(58.5)$ \\
Stress & $59(23.8)$ \\
Self-desire & $41(16.5)$ \\
Family & $3(1.2)$ \\
Number of quitting attempts among smokers & \\
Never & $33(13.3)$ \\
Once & $65(26.2)$ \\
$2-5$ times $>5$ times & $123(49.6)$ \\
$>5$ times & $27(10.9)$ \\
Methods of quitting attempts among smoking & \\
Never & $33(13.3)$ \\
Use of candy & $71(28.6)$ \\
Without intervention & $128(51.6)$ \\
Use of traditional medicine & $2(0.8)$ \\
Nicotine replacement & $12(4.8)$ \\
Others (e.g., exercise) & $2(0.8)$ \\
Number of cigarettes daily among smokers & \\
$<10$ & $125(50.4)$ \\
$11-20$ & $97(39.1)$ \\
$21-30$ & $23(9.3)$ \\
$\geq 31$ & $3(1.2)$ \\
\hline
\end{tabular}

Table 3: Association of smoking status and having family members who smoke

\begin{tabular}{|c|c|c|c|c|}
\hline \multirow[t]{2}{*}{ Variable } & \multicolumn{2}{|c|}{$\begin{array}{l}\text { Family member who } \\
\text { smoke, n (\%) }\end{array}$} & \multirow[t]{2}{*}{$\chi^{2}$} & \multirow[t]{2}{*}{$\mathbf{p}$} \\
\hline & Yes & No & & \\
\hline Nonsmoker & 157 (63.3) & 91 (36.7) & 67.03 & 0.000 \\
\hline Smoker & 232 (93.5) & $16(6.5)$ & & \\
\hline
\end{tabular}


Table 4: The distribution of FTND-M score of the smokers

\begin{tabular}{lll}
\hline FTND-M score & $\begin{array}{l}\text { Classification of nicotine } \\
\text { dependence }\end{array}$ & $\mathbf{n = 2 4 8}(\%)$ \\
\hline $0-2$ & Very low nicotine dependence & $128(51.6)$ \\
$3-4$ & Low nicotine dependence & $48(19.4)$ \\
5 & Moderate nicotine dependence & $31(12.5)$ \\
$6-7$ & High nicotine dependence & $28(11.3)$ \\
$8-10$ & Very high nicotine dependence & $13(5.2)$ \\
\hline
\end{tabular}

FTND-M: Malay version of Fagerstrom test for nicotine dependence

Smokers in this study group were mainly light smokers. Table 4 shows the distribution of FTND-M score in the smoker group. More than half of the participants, i.e., $51.6 \%(n=128)$, in this study had the FTND-M score lower than 2. Overall, the smokers in this study were not heavy smokers with only $5.2 \%(n=13)$ being considered as very high nicotine dependence.

\section{CONCLUSION}

Data obtained from this study later may also help the public health policy makers and health-care practitioners, especially in Kelantan, Malaysia, to make smoking prevention strategies more effective.

\section{ACKNOWLEDGMENT}

This project was supported by the short-term Research Grant (304/ PPSP/61313050) from University Sains Malaysia.

\section{REFERENCES}

1. Wolf PA, D'Agostino RB, Kannel WB, Bonita R, Belanger AJ. Cigarette smoking as a risk factor for stroke. The Framingham Study. JAMA 1988;259(7):1025-9.

2. Jajich CL, Ostfeld AM, Freeman DH Jr. Smoking and coronary heart disease mortality in the elderly. JAMA 1984;252(20):2831-4.

3. Rajesh V, Kumar BP, Kumaraswamy M, Rajveer S, Meenu P, Priyank T, et al. Smoking, alcohol and hypertension. Int J Pharm Pharm Sci 2013;5(4):28-32.

4. Lundbäck B, Lindberg A, Lindström M, Rönmark E, Jonsson AC, Jönsson E, et al. Not 15 but $50 \%$ of smokers develop COPD? - Report from the Obstructive Lung Disease in Northern Sweden Studies. Respir Med 2003;97(2):115-22.

5. Ueno M, Ohara S, Sawada N, Inoue M, Tsugane S, Kawaguchi Y. The association of active and secondhand smoking with oral health in adults: Japan public health center-based study. Tob Induc Dis 2015;131(1):19.

6. Gupta AK, Gupta MA, Summerbell RC, Cooper EA, Konnikov N, Albreski D, et al. The epidemiology of onychomycosis: Possible role of smoking and peripheral arterial disease. J Eur Acad Dermatol Venereol 2000;14(6):466-9.

7. Burns DN, Hillman D, Neaton JD, Sherer R, Mitchell T, Capps L, et al. Cigarette smoking, bacterial pneumonia, and other clinical outcomes in HIV-1 infection. Terry Beirn Community Programs for Clinical Research on AIDS. J Acquir Immune Defic Syndr Hum Retrovirol 1996;13(4):374-83.

8. Doll R, Peto R, Wheatley K, Gray R, Sutherland I. Mortality in relation to smoking: 40 years' observations on male British doctors. BMJ 1994;309(6959):901-11.

9. Lee J, Taneja V, Vassallo R. Cigarette smoking and inflammation: Cellular and molecular mechanisms. J Dent Res 2012;91(2):142-9.

10. Yusoff AF, Kaur G, Omar MA, Mustafa AN. Malaysian Burden of Disease and Injury Study. Malaysia: Institute for Public Health, National Institute of Health; 2005.

11. Priya N, Venkatalashmi P. The impact of heavy alcohol comsumption and cigarette smoking on liver function - A clinical survey. Int J Pharm Pharm Sci 2013;5:82-5.

12. Institute for Public Health (IPH). Report of the Global Adult Tobacco Survey (GATS) Malaysia, 2011. Malaysia: Ministry of Health Malaysia, IPH; 2012

13. Ford ES. Prevalence of the metabolic syndrome defined by the International Diabetes Federation among adults in the U.S. Diabetes Care 2005;28(11):2745-9.

14. Fagerström KO. Measuring degree of physical dependence to tobacco smoking with reference to individualization of treatment. Addict Behav 1978;3(3-4):235-41.

15. Yee AH, $\mathrm{Ng} \mathrm{C}$, Rusdi A. Validation of the Malay version of Fagerstrom test for nicotine dependence (FTND-M) among a group of male Staffs in a university hospital. Malays J Psychiatry 2011;20.

16. Centers for Disease Control and Prevention (CDC). State-specific prevalence of cigarette smoking among adults and quitting among persons aged 18-35 years - United States, 2006. MMWR Morb Mortal Wkly Rep 2007;56(38):993-6.

17. Abuelfoutoh A, El Tahlawy E, Hifnawy T. Knowledge, attitudes and practice with regard to the articles of the framework convention on tobacco control among Egyptian adults. J Taibah Univ Med Sci 2014;9(3):228-35

18. Jamal A, Agaku IT, O' Connor E, King BA, Kenemer JB, Neff L. Centers for disease control and prevention. Current cigarette smoking among adults-United States, 2005-2013. Morb Mortal Wkly Rep 2014;63(47):1108-12.

19. Kelly AB, O'Flaherty M, Connor JP, Homel R, Toumbourou JW, Patton GC, et al. The influence of parents, siblings and peers on pre-and early-teen smoking: A multilevel model. Drug Alcohol Rev 2011;30(4):381-7.

20. Bryant AL, Schulenberg J, Bachman JG, O’Malley PM, Johnston LD. Understanding the links among school misbehavior, academic achievement, and cigarette use: A national panel study of adolescents. Prev Sci 2000;1(2):71-87.

21. Williamson DF, Madans J, Anda RF, Kleinman JC, Giovino GA, Byers T. Smoking cessation and severity of weight gain in a national cohort. N Engl J Med 1991;324(11):739-45.

22. Huot I, Paradis G, Ledoux M; Quebec Heart Health Demonstration Project research group. Factors associated with overweight and obesity in Quebec adults. Int J Obes Relat Metab Disord 2004;28(6):766-74.

23. Chiolero A, Faeh D, Paccaud F, Cornuz J. Consequences of smoking for body weight, body fat distribution, and insulin resistance. Am J Clin Nutr 2008;87(4):801-9.

24. Audrain-McGovern J, Benowitz NL. Cigarette smoking, nicotine, and body weight. Clin Pharmacol Ther 2011;90(1):164-8.

25. Schindler-Ruwisch J, Augustson E, Lynch K, Patrick H. BMI and smoking: Interrelated factors among cessation website users. Am J Health Behav 2015;39(3):330-7.

26. Fukagawa NK, Bandini LG, Young JB. Effect of age on body composition and resting metabolic rate. Am J Physiol 1990;259(2):E233-8.

27. Mitchell WK, Williams J, Atherton P, Larvin M, Lund J, Narici M. Sarcopenia, dynapenia, and the impact of advancing age on human skeletal muscle size and strength; A quantitative review. Front Physiol 2012;3:260

28. Mikkelsen KL, Wiinberg N, Høegholm A, Christensen HR, Bang LE, Nielsen PE, et al. Smoking related to 24-h ambulatory blood pressure and heart rate: A study in 352 normotensive Danish subjects. Am J Hypertens 1997;10(5):483-91.

29. Benowitz NL, Sharp DS. Inverse relation between serum cotinine concentration and blood pressure in cigarette smokers. Circulation 1989;80(5):1309-12.

30. Von Ah D, Ebert S, Ngamvitroj A, Park N, Kang DH. Factors related to cigarette smoking initiation and use among college students. Tob Induc Dis 2005;3(1):27-40

31. Bawazeer AA, Hattab AS, Morales E. First cigarette smoking experience among secondary-school students in Aden, Republic of Yemen. East Mediterr Health J 1999;5(3):440-9.

32. Felimban FM, Jaralla JS. Smoking habits of secondary school boys in Riyadh, Saudi Arabia. Saudi Med J 1994;15(6):438-42.

33. Haddad LG, Malak MZ. Smoking habits and attitudes towards smoking among university students in Jordan. Int $\mathrm{J}$ Nurs Stud 2002;39(8):793-802.

34. Young D, Swan A, Melia J. Cigarette advertising and the youth market. Health Educ J 1989;48(3):113-6.

35. Robinson S, Bugler C. Smoking and Drinking Among Adults, 2008. General Lifestyle Survey 2008. London: ONS; 2010.

36. Kegler MC, Kingsley B, Malcoe LH, Cleaver V, Reid J, Soloman G. The functional value of smoking and non-smoking from the perspective of American Indian Youth. Fam Community Health 1999;22(2):31-42.

37. Smith KH, Stutts MA. Factors that influence adolescents to smoke. J Consum Aff 1999;33(2):321-57.

38. Khuder SA, Price JH, Jordan T, Khuder SS, Silvestri K. Cigarette smoking among adolescents in Northwest Ohio: Correlates of prevalence and age at onset. Int J Environ Res Public Health 2008;5(4):278-89.

39. So ES, Yeo JY Factors associated with early smoking initiation 
among Korean adolescents. Asian Nurs Res (Korean Soc Nurs Sci) 2015;9(2):115-9

40. Otten R, Engels RC, van de Ven MO, Bricker JB. Parental smoking and adolescent smoking stages: The role of parents' current and former smoking, and family structure. J Behav Med 2007;30(2):143-54.

41. Gilman SE, Rende R, Boergers J, Abrams DB, Buka SL, Clark MA, et al. Parental smoking and adolescent smoking initiation: An intergenerational perspective on tobacco control. Pediatrics 2009;123(2):e274-81.

42. Pennanen M, Vartiainen E, Haukkala A. The role of family factors and school achievement in the progression of adolescents to regular smoking. Health Educ Res 2012;27(1):57-68.

43. Oygard L, Klepp KI, Tell GS, Vellar OD. Parental and peer influences on smoking among young adults: Ten-year follow-up of the Oslo youth study participants. Addiction 1995;90(4):561-9.

44. Leonardi-Bee J, Jere ML, Britton J. Exposure to parental and sibling smoking and the risk of smoking uptake in childhood and adolescence: A systematic review and meta-analysis. Thorax 2011;66(10):847-55.

45. Ary DV, Biglan A. Longitudinal changes in adolescent cigarette smoking behavior: Onset and cessation. J Behav Med 1988;11(4):361-82. 